\title{
Developing Empirical Relationship between Interrill Erosion, Rainfall Intensity, Slope Gradient and Soil Types in Highlands of Salale, Ethiopia
}

\author{
Habtamu Adenew Weletu*
}

Faculty of Resource Management and Economics, Wollega University, P.O. Box: 395, Nekemte, Ethiopia \begin{abstract}
In order to develop an empirical relationship for interrill erosion based on rainfall intensity, slope steepness and soil types, an interrill erosion experiment was conducted using laboratory rainfall simulator on three soil types (Vertisols, Cambisols and Leptosols) for the highlands of North Shewa Zone of Oromia Region. From simulation work done using $450 \mathrm{x}$ $320 \times 100 \mathrm{~mm}$ erosion test pan; splashed soils, runoff and washed soils were collected at 5 minute interval for each 15 minutes simulation run at various combinations of design rainfall intensities of $25.67,52.14,73.50$, and $99.20 \mathrm{mmhr}^{-1}$, slope steepness of $5,20,35$, and $50 \%$ and the three soil types. Runoff rate, splash and wash loss were measured to obtain a total soil loss from the test pan. Different models relating interrill erosion with rainfall intensity and runoff rate were considered and their coefficients and parameters were estimated. From the models, those with highest prediction potential $\left(R^{2}\right)$ were selected to be incorporated into models consisting soil properties and used to form six basic models of which three of them had shown average $\mathrm{R}^{2}$ values of more than 0.95 . Accordingly, five slope factor equations were combined with the three selected models and thus 15 models were formed. Out of these models, three of them had shown $\mathrm{R}^{2}>0.90$ and were further compared with each other using the graph plotted for observed versus predicted interrill erosion. This showed that model incorporating rainfall intensity, runoff rate, median soil particle diameter, \% clay and quadratic form of slope factor carried higher prediction potential than the other two models and selected as the final model for predicting interrill erosion. As this model incorporates more factors than those previously developed models, it ensures more accurate estimation of interrill erosion.
\end{abstract}

Copyright@2016 STAR Journal, Wollega University. All Rights Reserved.

\author{
Article Information \\ Article History: \\ Received : 16-01-2016 \\ Revised : 19-03-2016 \\ Accepted : 22-03-2016
}

Keywords:

Interrill erosion

Empirical equations

Erosion models

${ }^{*}$ Corresponding Author:

Habtamu Adenew

E-mail:

sinanhaw29@gmail.com

\section{INTRODUCTION}

Ethiopia is among the Sub-Saharan African countries where soil erosion by water constitutes the most widespread and damaging process of land degradation (Gete and Hurni, 2001). As suggested by Soil Conservation Research Projects (SCRP, 1990), this process has been accelerated by population growth (due to deforestation and expansion of agricultural production into marginal lands) and due to intense tropical rainfall and the dissected nature of the terrain with nearly $70 \%$ of the highlands having slopes in excess of $30 \%$ over which erosion by water is dominant.

Interrill erosion is one form of water erosion that seriously affects the most productive top soil of cultivated lands. It occurs on an area where detachment of soil particles is caused mainly by raindrop impact, and simultaneously, transportation takes place by splash and raindrop- induced shallow overland flow. According to Bradford et al. (1987), in interrill area, the flow alone can transport only the smallest particles, but raindrop impact on this flow entrains larger particles and significantly increase the thin flow transport capacity so that transportation of detached soil particles can be carried by raindrop induced interrill flow.
The relationship existing between interrill erosion and factors affecting it were previously evaluated by several researchers (Libenow et al., 1990; Fox and Bryan, 1999). However, these relationships were empirically driven and affected by the levels of factors considered and their interactions. Several equations relating rainfall intensity, runoff rate and slope gradient to interrill erosion were also evaluated in previous studies (Zhang et al., 2003; Jayawardena and Rezaur, 2006) and the results revealed that these relationships were empirically derived and were characterized as unique functions of soil properties, rainfall intensity, surface soil conditions and erosion processes. Most of the empirical equations which were developed so far between interrill erosion and major factors affecting it consider only few factors and are also dependent on local situations. Hence, for proper management of interrill area, there is a need to consider several factors and develop an empirical relationship that better relates interrill erosion with factors influencing it under a wide range of situations. Therefore, the study was conducted to develop appropriate models relating interrill erosion with rainfall intensity, runoff rate, slope steepness and major soil types and to estimate coefficients and parameters for the empirical equations. 


\section{MATERIALS AND METHODS}

\section{Description of the Study Area}

The study was carried out in the highlands of North Shewa Zone of Oromia Region, which is situated between $9^{0} 09^{\prime} \mathrm{N}$ to $10^{\circ} 39^{\prime} \mathrm{N}$ latitude and $38^{\circ} 85^{\prime} \mathrm{E}$ to $39^{\circ} 52^{\prime} \mathrm{E}$ longitude. The study area has an altitude of 1500 to 3480 m.a.s.l., the mean annual rainfall of $1500 \mathrm{~mm}$ and the mean annual temperature of $16^{\circ} \mathrm{C}$. The major soils include Vertisols, Cambisols, Leptosols and Luvisols in widely diversified distribution and the dominant land use types are cultivable land and a parcel of grazing land.

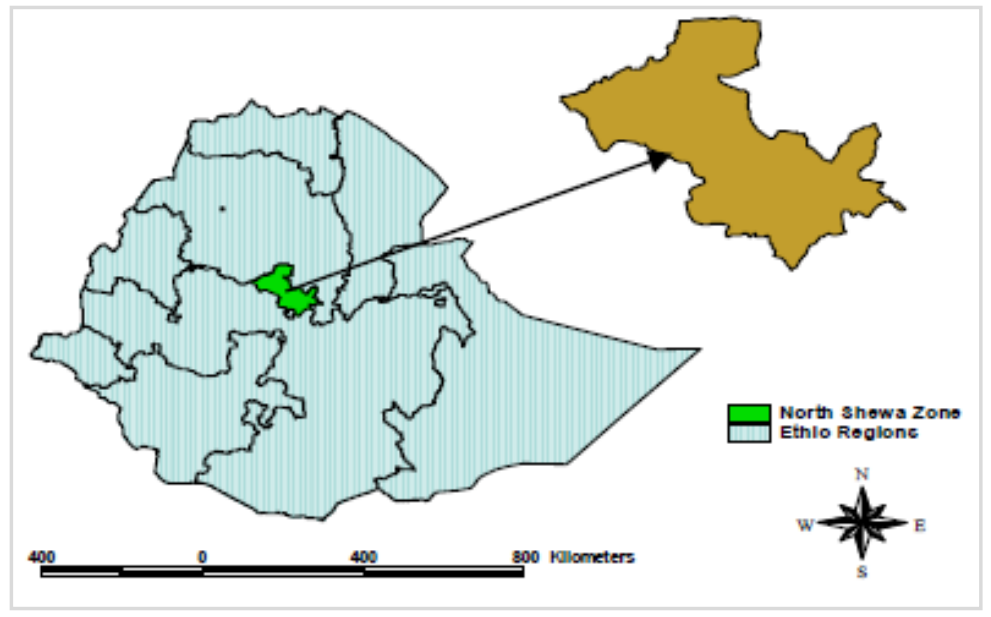

Figure 1: Location Map of the Study Site

\section{Site and Treatment Selection}

Of the 14 Woredas in the Zone, mainly, nine of them (Grar-Jarso, Dagam, Kuyu, Wachale, Jidda, Shano, Aleletu, Yaya-Gulele, and Mulo) fall partially or fully under the highland agro-climate from where the soil samples were taken. Soils with a wide range of physico-chemical properties,large areal coverage and higher agricultural importance were selected from the cultivated lands in the highlands of the Zone as Vertisols, Cambisols and Leptosols. The treatments for this study consisted of three soil types (Vertisols, Cambisols and Leptosols), four rainfall intensities $\left(25,50,75\right.$ and $\left.100 \mathrm{mmhr}^{-1}\right)$, and four slope gradients $(5,20,35$ and $50 \%)$ with three replications.

\section{Soil Sampling and Analysis}

Samples were collected for simulation test and analysis of some soil physical properties. During sampling, $10 \mathrm{~m} \times 10 \mathrm{~m}$ plot size was equally divided by rods into 5 equal parts giving 25 grids from where the samples were collected in a systematic way from the surface layer of $20 \mathrm{~cm}$. The selected soil physical property with their respective method of analysis includes: soil texture (hydrometer), soil bulk density (core method), aggregate stability (wet sieving), $\mathrm{D}_{50}$ (Sieve analysis) and soil shear strength (Swedish fall-cone penetro-meter).

\section{Interrill Erosion Experiment in the Laboratory using Simulated Rainfall}

The interrill erosion experiment was conducted in a laboratory using FEL-3 rainfall simulator and erosion test pans with dimension of $450 \mathrm{~mm} \times 320 \mathrm{~mm} \times 100 \mathrm{~mm}$ (used by Le Bissonnais (1996)) with a splash shield on the four sides and a gutter on down slope side to collect washed soil loss and runoff. Accordingly, for the proposed intensities of $25,50,75$ and $100 \mathrm{~mm} \mathrm{hr}^{-1}$, actual intensities of $25.67,52.14,73.50$ and $99.20 \mathrm{~mm} \mathrm{hr}^{-1}$ with coefficients of uniformity of $83,83,84$ and $82 \%$ were used for the actual erosion experiment. For interrill erosion experiment, the soil sample was packed in erosion test pan and by keeping the moisture content at field capacity, the simulation started with desired intensity by adjusting the plot to the desired slope. The simulation was done for 15 minutes during which 3 splash and runoff yields were collected at 5 minute interval.

The runoff collected in the cylindrical container at the interval of 5 minutes at each run was measured to obtain the runoff volume. The dry mass of the soil washed was obtained from sediment in the container after decantation and oven dry at $105^{\circ} \mathrm{C}$. The amount of soil splashed during the run was also oven dried, weighed separately and combined with dry mass of washed soil and finally interrill erosion rate $\left(\mathrm{g} \mathrm{m}^{-2} \mathrm{hr}^{-1}\right)$ and runoff rate $\left(\mathrm{cm}^{3} \mathrm{~min}^{-1}\right.$ per $\mathrm{cm}$ width of the test pan) was estimated.

\section{RESULTS}

\section{Selected Soil Physical Properties}

The analysis results of some of the soil physical properties (Table 1) show that the textural classes of the soils were clay, clay loam and sandy clay loam for Vertisols, Cambisols and Leptosols, respectively. The bulk density for the three soils range from 1.21 to $1.46 \mathrm{~g} \mathrm{~cm}^{-3}$.

Table1: Analysis results for selected soil physical properties

\begin{tabular}{|c|c|c|c|c|c|c|c|c|}
\hline \multirow{2}{*}{ Soil type } & \multicolumn{3}{|c|}{ Particle size distribution (\%) } & \multirow{2}{*}{$\begin{array}{l}\text { Textural } \\
\text { classes }\end{array}$} & \multirow{2}{*}{$\begin{array}{c}\text { Water stable } \\
\text { aggregate } \\
\text { (WSA \%) }\end{array}$} & \multirow{2}{*}{$\begin{array}{l}\text { Bulk density } \\
\left(\mathrm{gcm}^{-3}\right)\end{array}$} & \multirow{2}{*}{$\begin{array}{c}d_{50} \\
(\mu \mathrm{m})\end{array}$} & \multirow{2}{*}{$\tau\left(\mathrm{KN} / \mathrm{m}^{2}\right)$} \\
\hline & Sand & Silt & Clay & & & & & \\
\hline Vertisols & 11.08 & 25.20 & 63.72 & Clay & 61 & 1.21 & 1.45 & 5.413 \\
\hline Cambisols & 26.28 & 35.60 & 38.12 & clay loam & 54 & 1.33 & 2.25 & 2.995 \\
\hline Leptosols & 49.63 & 21.48 & 28.89 & Sandy clay loam & 37 & 1.46 & 9.03 & 2.034 \\
\hline
\end{tabular}




\section{Habtamu Adenew Weletu}

The result from aggregate stability analysis as expressed in percent water stable aggregates was indicated as Vertisols (61\%), Cambisols (54\%) and Leptosols (37\%). Median soil particle diameters $\left(d_{50}\right)$ and the shear strength of the soils were found to be 1.45 , $2.25,9.03 \mu \mathrm{m}$ and $5.413,2.995,2.034 \mathrm{KN} / \mathrm{m}^{2}$ respectively, for the three soils.

Runoff Rates \& Soil Losses from the Three Soil Types at Different Slope Steepness and Rainfall Intensities

The comparison of runoff rate in terms of soil types indicated that, under a given rainfall intensity; runoff rate
Sci. Technol. Arts Res. J., Jan-March 2016, 5(1): 51-60

was generally high for Cambisols and low for Leptosols while an intermediate for Vertisols implying that Cambisols are more erodible relative to the other two. The rate of soil loss for the three soils varied with variation in slope steepness and rainfall intensities. The result of average soil loss rate (Table 2) showed that under each rainfall intensity, average soil loss rate tends to increase with an increase in slope steepness. Likely, under all rainfall intensities, average soil loss rate seems to increase.

Table 2: Average runoff rate $\left(\mathrm{cm}^{3} \mathrm{~min}^{-1} \mathrm{~cm}^{-1}\right)$ and soil loss rate $\left(\mathrm{g} \mathrm{m}^{-2} \mathrm{hr}^{-1}\right)$ for the three soils at different slope steepness and rainfall intensities

\begin{tabular}{|c|c|c|c|c|c|c|c|c|c|}
\hline \multirow{3}{*}{ Soil types } & \multirow{3}{*}{$\begin{array}{c}\text { Slope } \\
\text { (\%) }\end{array}$} & \multicolumn{8}{|c|}{ Rainfall intensities * } \\
\hline & & \multicolumn{2}{|c|}{$I_{25.67}$} & \multicolumn{2}{|c|}{$I_{52.14}$} & \multicolumn{2}{|c|}{$I_{73.50}$} & \multicolumn{2}{|c|}{$I_{99.20}$} \\
\hline & & Q & SL & Q & SL & Q & SL & Q & SL \\
\hline \multirow{5}{*}{ Leptosols } & 5 & 0.297 & 41.08 & 0.415 & 58.55 & 0.601 & 86.08 & 2.990 & 427.60 \\
\hline & 20 & 0.534 & 75.17 & 1.273 & 181.80 & 4.614 & 658.23 & 4.097 & 584.29 \\
\hline & 35 & 1.351 & 192.40 & 1.485 & 211.01 & 6.082 & 868.37 & 5.259 & 750.73 \\
\hline & 50 & 2.430 & 346.92 & 2.374 & 339.42 & 5.613 & 722.78 & 6.214 & 887.58 \\
\hline & average & 1.153 & 163.89 & 1.386 & 197.69 & 4.227 & 583.86 & 4.640 & 662.55 \\
\hline \multirow{5}{*}{ Vertisols } & 5 & 0.705 & 93.01 & 1.76 & 280.09 & 3.881 & 554.18 & 3.335 & 476.01 \\
\hline & 20 & 0.843 & 120.30 & 1.919 & 253.94 & 4.157 & 592.44 & 6.514 & 929.72 \\
\hline & 35 & 4.276 & 569.09 & 5.056 & 672.59 & 6.372 & 1237.55 & 6.081 & 1539.14 \\
\hline & 50 & 4.127 & 549.57 & 5.067 & 673.81 & 5.651 & 1236.36 & 5.934 & 1288.69 \\
\hline & average & 2.487 & 412.98 & 3.450 & 470.10 & 5.015 & 905.13 & 5.466 & 1058.39 \\
\hline \multirow{5}{*}{ Cambisols } & 5 & 1.676 & 222.70 & 2.436 & 324.69 & 3.530 & 503.70 & 6.210 & 887.38 \\
\hline & 20 & 3.221 & 500.48 & 3.405 & 486.03 & 6.753 & 965.02 & 6.664 & 951.94 \\
\hline & 35 & 3.206 & 460.04 & 3.854 & 686.61 & 8.381 & 1072.14 & 7.721 & 1102.20 \\
\hline & 50 & 3.751 & 570.89 & 6.391 & 913.19 & 7.519 & 1197.74 & 10.763 & 1537.38 \\
\hline & average & 2.701 & 394.40 & 4.021 & 602.63 & 6.221 & 934.65 & 7.839 & 1119.72 \\
\hline
\end{tabular}

${ }^{*} \mathrm{I}_{25.67}=25.67 \mathrm{~mm} \mathrm{hr}^{-1}$ rainfall intensity, $\mathrm{I}_{52.14}=52.14 \mathrm{~mm} \mathrm{hr}^{-1}$ rainfall intensity, $\mathrm{I}_{73.50}=73.50 \mathrm{~mm} \mathrm{hr}^{-1}$ Rainfall intensity, $I_{99.20}=99.20 \mathrm{~mm} \mathrm{hr}^{-1}$ rainfall intensity, Runoff rate $(\mathrm{Q})=\left(\mathrm{cm}^{3} \mathrm{~min}^{-1} \mathrm{~cm}^{-1}\right)$ and Soil loss rate $(\mathrm{SL})\left(\mathrm{g} \mathrm{m}^{-2} \mathrm{hr}^{-1}\right)$.

\section{DISCUSSION}

\section{Relationship between Interrill Erosion and Rainfall Intensity}

To estimate the empirical constants of the power equation that relates interrill erosion and rainfall intensity (Model 1), the experimental data from the simulation for the duration of $0-15$ minutes were grouped by soil types and slope steepness, and parameters $a$ and $b$ were estimated by linear regression of log transformed data.

$$
E_{i}=a l^{b}
$$

Where, $E_{i}=$ Interrill erosion rate $\left(\mathrm{g} \mathrm{m}^{-2} \mathrm{hr}^{-1}\right), \mathrm{I}=$ intensity $\left(\mathrm{mm} \mathrm{hr}^{-1}\right)$ and $a \& b$ are best fit local constants.

This power equation was used by several researchers like Goff et al. (2000), Mengistu (2003), and Agarwal and Dickinson (2005), and recommended that it best relate interrill erosion and rainfall intensity. In this study also, the values of parameter $a$ and $b$ were estimated to be in the range of 0.37 to 97.36 and 0.01 to 4.53 for the three soils, respectively and the results agree with the one explained by Fox and Bryan (1999) after conducting an experiment on two soils (Vertisols and Nitosols). Averaged values of $b$ for the three soils were found to be in the range of 1.29 to 2.14. This result agrees with the suggestion given by Meyer (1994) as the power equation with a value of $b=2$ could describe the process of interrill erosion mainly for Leptosols and Cambisols. For the three soils, $\mathrm{R}^{2}$ value has an average value of $0.90,0.92$ and 0.95 for Leptosols, Vertisols and Cambisols, respectively. It consistently increased with an increase in slope steepness only for Vertisols.

Table 3: Estimated values of coefficients and exponents for the model I. Model I $\left(E_{i}=a l^{b}\right)$ *

\begin{tabular}{ccccc}
\hline Soil type & Slope (\%) & $\mathbf{a}$ & $\boldsymbol{b}$ & $\mathbf{R}^{\mathbf{2}}$ \\
\hline \multirow{5}{*}{ Leptosols } & 5 & 0.58 & 1.98 & 0.79 \\
& 20 & 0.37 & 1.78 & 0.95 \\
& 35 & 9.35 & 2.59 & 0.87 \\
& 50 & 95.60 & 0.56 & 0.99 \\
\cline { 2 - 5 } Vertisols & Average & $\mathbf{2 6 . 4 8}$ & $\mathbf{1 . 4 8}$ & $\mathbf{0 . 9 0}$ \\
\hline \multirow{5}{*}{ Cambisols } & 5 & 0.81 & 0.01 & 0.83 \\
& 20 & 0.90 & 1.98 & 0.89 \\
& 35 & 58.11 & 1.53 & 0.97 \\
& 50 & 74.66 & 1.65 & 0.98 \\
\cline { 2 - 5 } & Average & $\mathbf{3 3 . 6 2}$ & $\mathbf{1 . 2 9}$ & $\mathbf{0 . 9 2}$ \\
\cline { 2 - 5 } & 5 & 12.32 & 0.85 & 0.87 \\
& 20 & 64.65 & 1.70 & 0.98 \\
\cline { 2 - 5 } & Average & 94.84 & 1.48 & 0.95 \\
& $\mathbf{6 7 . 2 9}$ & $\mathbf{2 . 1 4}$ & $\mathbf{0 . 9 5}$
\end{tabular}

${ }^{*} \mathrm{E}_{\mathrm{i}}\left(\mathrm{g} \mathrm{m}^{-2} \mathrm{hr}^{-1}\right), \mathrm{I}\left(\mathrm{mm} \mathrm{hr}^{-1}\right), a$ and $b$ are parameters of best fit, $\mathrm{R}^{2}=$ Coefficient of determination

The average $R^{2}$ value for the three soils showed that this power equation could describe interrill erosion better on both soils though it has high prediction potential for Cambisols with $\mathrm{R}^{2}$ value of 0.95 . 


\section{Habtamu Adenew Weletu}

\section{Relationship between Rainfall Intensity, Runoff Rate} and Interrill Erosion

In order to incorporate runoff rate, models with nonlinear and linear terms of rainfall intensities were considered for interrill erosion processes as presented below:

$$
\begin{aligned}
& E_{i}=a l^{b} Q^{n} \\
& E_{i}=a l Q^{n}
\end{aligned}
$$

Where, $E_{i}=$ interrill sediment delivery per unit area per unit time $\left(\mathrm{g} \mathrm{m}^{-2} \mathrm{hr}^{-1}\right)$, I is rainfall intensity $\left(\mathrm{mm} \mathrm{hr}^{-1}\right), \mathrm{Q}$ is Runoff rate $\left(\mathrm{cm}^{3} \mathrm{~min}^{-1} \mathrm{~cm}^{-1}\right)$ and $\mathrm{a}, \mathrm{b}$ and $\mathrm{n}$ are best fit local constants.

For estimating coefficient and exponent values of these empirical equations, the data from duration of 5 15 minutes were grouped by soil type and slope, and linear regression of log transformed data was used to estimate the parameters. From the analysis results (Table 4 ), it could be observed that the values of a for models II
Sci. Technol. Arts Res. J., Jan-March 2016, 5(1): 51-60

and III varied from 0.017 to 7.052 and 0.256 to 3.092 respectively

The estimated values of $b$ for model II ranged from 0.071 to 5.847 and for each soil types, it had an increasing trend with increase in slope steepness. This could be in agreement with the values reported by Grosh and Jarret (2004) after conducting an experiment on disturbed silty clay loam. Estimated values of $n$ for model II has variable values and it agrees with the results reported by Agarwal and Dickinson (2005) as an average values of $n$ ranging from -2.86 to 2.88 and suggested that the average value of $n$ for model with linear term of rainfall intensity was increased with slope steepness. Coefficients of determination for model II were found to be more than 0.87 with average values of $0.92,0.95$ and 0.98 for Leptosols, Vertisols and Cambisols, respectively. These values of $R^{2}$ showed that this model could predict interrill erosion on all three soils in a better way. Meyer (1994) reported values of $\mathrm{R}^{2}$ greater than 0.90 for similar models by confirming that it better predicted interrill erosion for their study condition.

\begin{tabular}{|c|c|c|c|c|c|c|c|c|}
\hline \multirow{2}{*}{ Soil types } & \multirow{2}{*}{$\begin{array}{c}\text { Slope } \\
(\%)\end{array}$} & \multicolumn{4}{|c|}{ Model II $\left(E_{i}=a I^{b} Q^{n}\right)^{*}$} & \multicolumn{3}{|c|}{ Model III $\left(E_{i}=\mathrm{alQ}^{\mathrm{n}}\right)^{\star}$} \\
\hline & & $a$ & $\boldsymbol{b}$ & $n$ & $\mathbf{R}^{2}$ & $a$ & $n$ & $\mathbf{R}^{2}$ \\
\hline \multirow{5}{*}{ Leptosols } & 5 & 0.943 & 0.256 & -0.046 & 0.87 & 2.923 & 1.087 & 0.79 \\
\hline & 20 & 0.997 & 1.253 & -0.052 & 0.91 & 1.171 & 0.365 & 0.73 \\
\hline & 35 & 1.018 & 1.459 & 0.234 & 0.96 & 1.263 & 0.955 & 0.91 \\
\hline & 50 & 3.615 & 3.615 & 0.405 & 0.94 & 1.086 & 1.572 & 0.86 \\
\hline & Average & 1.643 & 1.645 & 0.135 & 0.92 & 1.610 & 0.994 & 0.82 \\
\hline \multirow{5}{*}{ Vertisols } & 5 & 0.035 & 0.299 & -0.397 & 0.92 & 2.186 & -2.225 & 0.83 \\
\hline & 20 & 1.027 & 1.405 & -0.096 & 0.97 & 1.201 & 0.444 & 0.91 \\
\hline & 35 & 1.058 & 3.161 & -0.423 & 0.94 & 7.086 & 1.482 & 0.86 \\
\hline & 50 & 3.033 & 5.847 & 0.965 & 0.99 & 11.09 & 1.445 & 0.87 \\
\hline & Average & 1.288 & 2.678 & 0.012 & 0.95 & 5.390 & 0.287 & 0.86 \\
\hline \multirow{5}{*}{ Cambisols } & 5 & 0.017 & 0.071 & -0.325 & 0.97 & 0.256 & -1.843 & 0.84 \\
\hline & 20 & 0.994 & 1.663 & -0.535 & 0.98 & 1.031 & 1.532 & 0.85 \\
\hline & 35 & 0.998 & 3.349 & 1.186 & 0.99 & 9.005 & 0.405 & 0.92 \\
\hline & 50 & 7.052 & 4.154 & 2.727 & 0.99 & 13.092 & 1.463 & 0.91 \\
\hline & Average & 2.265 & 2.309 & 0.170 & 0.98 & 5.846 & 0.389 & 0.88 \\
\hline
\end{tabular}

Table 4: Estimated values of the parameters for model II and III

${ }^{\star} E_{i}\left(\mathrm{~g} \mathrm{~m}^{-2} \mathrm{hr}^{-1}\right), \mathrm{I}\left(\mathrm{mm} \mathrm{hr}^{-1}\right)$ and $\mathrm{Q}\left(\mathrm{cm}^{3} \mathrm{~min}^{-1} \mathrm{~cm}^{-1}\right), \mathrm{R}^{2}$ is coefficient of determination

For model III, $\mathrm{R}^{2}$ have average values of $0.82,0.86$ and 0.88 respectively, for the three soils showing that model III has lower potential than model II in predicting interrill erosion on the three soils.

From the average values of $\mathrm{R}^{2}$ at each slope steepness, it could be possible to observe that, since the $\mathrm{R}^{2}$ values of model II were greater than that of model III, generally model with non-linear intensity term $\left(E_{i}=a l^{b} Q^{n}\right)$ described the interrill erosion process better than that with linear intensity term $\left(E_{i}=a l Q^{n}\right)$ at each slope steepness for the three soils. Likely, Le Bissonnais and Singer (2003) tried to incorporate the model with non-linear term of rainfall intensity in their experiment and found that it better described interrill erosion than model with linear rainfall intensity term with $\mathrm{R}^{2}$ greater than 0.88 . Therefore, from the three models (model I, II and III), comparison of their respective average $R^{2}$ values for the three showed that the first two models had relatively higher $R^{2}$ values than the last model implying that they could better describe interrill erosion on the three soils, and were selected to be further incorporated into other models.

Relationship between Rainfall Intensity, Runoff Rate, Soil Physical Properties and Interrill Erosion

Among others, Sheridan et al. (2007) had conducted experiments to see the effects of some soil physical properties on interrill erosion and finally reported that, soil shear strength, \% clay content and median soil particle diameter mainly influence the nature of interrill erosion. Similarly, in the present study as well, these soil properties were selected and models which relate them with interrill erosion were incorporated into the above selected models (model I and II), and formed six basic models that would be further evaluated to select an appropriate model that best describes interrill erosion. The data collected were grouped for slope steepnesses and the parameters were estimated by non-linear regression analysis. The models obtained were of the form:

$E_{i}=a l^{b} \tau^{y} d_{50}{ }^{z}$

$E_{i}=a^{b} \tau^{y}$ (\%clay) ${ }^{x}$

$E_{i}=a^{b} d_{50}^{z}$ (\%clay)

$E_{i}=a^{b} Q^{n} \tau^{y} d_{50}{ }^{z}$

$E_{i}=a^{b} Q^{n} \tau^{y}(\% \text { clay })^{x}$

$\mathrm{E}_{\mathrm{i}}=\mathrm{al}^{\mathrm{b}} \mathrm{Q}^{\mathrm{n}} \mathrm{d}_{50}{ }^{\mathrm{z}}$ (\%clay) ${ }^{\mathrm{x}}$
$(\mathrm{V})$ 


\section{Habtamu Adenew Weletu}

Where, $E_{i}$ is interrill erosion rate $\left(\mathrm{g} \mathrm{m}^{-2} \mathrm{hr}^{-1}\right), \mathrm{I}$ is rainfall intensity $\left(\mathrm{mm} \mathrm{hr}^{-1}\right), \mathrm{Q}$ is runoff rate $\left(\mathrm{cm}^{3} \mathrm{~min}^{-1} \mathrm{~cm}^{-1}\right), \mathrm{T}$ is soil shear strength $\left(\mathrm{KN} \mathrm{m}^{-2}\right), \mathrm{d}_{50}$ is median soil particle diameter $(\mu \mathrm{m}), a, b, n, x, y, z$ are parameters to be estimated.

Based on the estimated values of parameters for the six models (Table 5), the value of $a, b$, and $n$ ranged from 0.474 to $21.042, \quad 0.248$ to 2.911 and 0.009 to 1.043 respectively. For these three models there was a general tendency of increase in $n$ with increase in slope steepness showing that as slope steepness increases, runoff rate also increases, which in turn increases soil loss rate. Similarly, researchers like (Fan and Wu, 2001) reported that runoff rate increases with an increase in slope steepness.

The values of $x$ in the models relating clay percentage to soil loss by interrill erosion has an average values of -
Sci. Technol. Arts Res. J., Jan-March 2016, 5(1): 51-60

$0562,-0.669,-0.417$ and -0.595 , respectively. No consistent trend was observed between estimated values of $x$ and slope steepness though the negative values shows that the higher the clay contents, the lower would be the interrill erosion. For the models containing shear strength, the estimated values of $y$, in the case of this study, ranged from-1.058 to -0.046 in which the negative values show that there is an inverse relationship between soil shear strength and soil loss. This result was in agreement with results reported by Sheridan et al., (2007) who found values of $y$ ranging from -0.43 to -0.40 under variable slope steepness and rainfall intensity. Likely, the estimated values of $z$ in model relating median soil particle diameter with interrill erosion rate has an average values of $-0.386,-1.106,-0.903$ and -0.617 , respectively indicating that as $d_{50}$ increases soil loss rate decreases due to the fact that the higher the particle sizes the lower would be the ease of transport.

Table 5: Estimated values of the parameters for the selected six models

\begin{tabular}{|c|c|c|c|c|c|c|c|c|}
\hline Models & Slope(\%) & $a$ & $b$ & $n$ & $x$ & $y$ & $z$ & $\mathbf{R}^{2}$ \\
\hline \multirow{5}{*}{$\begin{array}{c}\text { Model IV } \\
E_{i}=a^{b} \tau^{y} d_{50}^{z}\end{array}$} & 5 & 1.691 & 1.032 & - & - & -0.046 & -0.007 & 0.71 \\
\hline & 20 & 0.474 & 1.457 & - & - & -0.262 & -0.083 & 0.83 \\
\hline & 35 & 13.455 & 1.944 & - & - & -0.417 & -0.513 & 0.87 \\
\hline & 50 & 21.042 & 1.993 & - & - & -0.901 & -0.942 & 0.90 \\
\hline & Ave. & 9.165 & 1.607 & - & - & -0.406 & -0.386 & 0.83 \\
\hline \multirow{5}{*}{$\begin{array}{c}\text { Model V } \\
E_{i}=a^{b} \tau^{y}(\% \text { clay })^{x}\end{array}$} & 5 & 3.721 & 0.248 & - & -0.674 & -0.921 & - & 0.92 \\
\hline & 20 & 0.545 & 0.871 & - & -0.596 & -0.743 & - & 0.99 \\
\hline & 35 & 2.972 & 2.053 & - & -0.505 & -0.931 & - & 0.98 \\
\hline & 50 & 1.074 & 2.911 & - & -0.473 & -1.058 & - & 0.96 \\
\hline & Ave. & 2.078 & 1.521 & - & -0.562 & -0.913 & - & 0.96 \\
\hline \multirow{5}{*}{$\begin{array}{c}\text { Model VI } \\
\left.\mathrm{E}_{\mathrm{i}}=\mathrm{al}^{\mathrm{b}} \mathrm{d}_{50}{ }^{\mathrm{z}} \text { clay }\right)^{\mathrm{x}}\end{array}$} & 5 & 1.931 & 0.738 & - & 1.073 & - & -1.337 & 0.85 \\
\hline & 20 & 1.952 & 0.966 & - & -0.902 & - & -1.391 & 0.87 \\
\hline & 35 & 2.017 & 1.062 & - & -0.347 & - & -0.805 & 0.92 \\
\hline & 50 & 0.573 & 1.719 & - & -0.352 & - & -0.892 & 0.90 \\
\hline & Ave. & 1.618 & 1.121 & - & -0.669 & - & -1.106 & 0.88 \\
\hline \multirow{5}{*}{$\begin{array}{c}\text { Model VII } \\
\mathrm{E}_{\mathrm{i}}=\mathrm{al}^{\mathrm{b}} \mathrm{Q}^{\mathrm{n}} \tau^{\mathrm{y}} \mathrm{d}_{50} \mathrm{z}\end{array}$} & 5 & 4.071 & 2.381 & 0.058 & - & -0.066 & -0.843 & 0.87 \\
\hline & 20 & 7.151 & 1.942 & 0.692 & - & -0.583 & -0.807 & 0.89 \\
\hline & 35 & 3.094 & 0.731 & 0.921 & - & -0.147 & -0.917 & 0.86 \\
\hline & 50 & 16.01 & 0.897 & 1.043 & - & -0.803 & -1.045 & 0.91 \\
\hline & Ave. & 7.582 & 1.487 & 0.678 & - & -0.399 & -0.903 & 0.88 \\
\hline \multirow{5}{*}{$\mathrm{E}_{\mathrm{i}}=\mathrm{al}^{\mathrm{b}} \mathrm{Q}^{\mathrm{n}} \tau^{\mathrm{y}}(\% \text { clay })^{\mathrm{x}}$} & 5 & 1.094 & 1.944 & 0.031 & -0.392 & -0.074 & - & 0.95 \\
\hline & 20 & 5.173 & 2.817 & 0.031 & -0.104 & -0.536 & - & 0.98 \\
\hline & 35 & 2.037 & 2.201 & 0.647 & -0.463 & -0.773 & - & 0.97 \\
\hline & 50 & 2.572 & 1.504 & 0.593 & -0.709 & -0.944 & - & 0.99 \\
\hline & Ave. & 2.719 & 2.116 & 0.325 & -0.417 & -0.581 & - & 0.98 \\
\hline \multirow{5}{*}{$\begin{array}{c}\text { Model IX } \\
E_{i}=\left.a\right|^{b} Q^{n} d_{50}{ }^{z}(\% \text { clay })^{x}\end{array}$} & 5 & 2.249 & 1.913 & 0.009 & -0.964 & - & -0.185 & 0.94 \\
\hline & 20 & 1.981 & 2.579 & 0.025 & -0.913 & - & -0.408 & 0.98 \\
\hline & 35 & 1.542 & 2.841 & 0.377 & -0.255 & - & -0.904 & 0.96 \\
\hline & 50 & 1.353 & 0.901 & 0.246 & -0.247 & - & -0.971 & 0.97 \\
\hline & Ave. & 1.781 & 2.059 & 0.164 & -0.594 & - & -0.617 & 0.96 \\
\hline
\end{tabular}

At 5 and 20\% slope steepness, models V, VIII and IX describe interrill erosion better than the other models (with their $\mathrm{R}^{2}$ values greater than 0.90 ), while the other models has the least potential with their $\mathrm{R}^{2}$ value less than 0.90 (Table 5). Still at slope steepness of $35 \%$, model V, VIII and IX have higher coefficient of determination. From the comparison of the average efficiencies for each of the models, $\mathrm{R}^{2}$ value for model V, VIII and IX were greater than that of the others showing that these three models had higher potential to predict interrill erosion at all slope steepness's. Therefore, model V, VIII and IX were selected and used in the complete statistical modeling in which slope factors were incorporated.

\section{Relationship between Slope Steepness and Interrill Erosion}

To investigate the effect of slope steepness on interrill erosion, the rate of interrill soil loss for duration of 15 minutes and slope steepness for the three types of soils with four different intensities were plotted as shown in figures 2 to 5 . From figure 2, the soil loss rates for Vertisols and Cambisols initially increased at a decreasing 


\section{Habtamu Adenew Weletu}

rate with an increase in slope steepness and above $35 \%$ slope steepness it increased on both soils with the same fashion. This might be due to the nature of the soil with high clay content as it initially swells and holds water and difficult to be detached (Mc Cool et al., 1997). Under a rainfall intensity of $52.14 \mathrm{~mm} \mathrm{hr}^{-1}$ (Figure 3), soil loss rate for Vertisols and Cambisols generally tends to increase with higher rate for Cambisols under all slope
Sci. Technol. Arts Res. J., Jan-March 2016, 5(1): 51-60

steepnesses. For $73.50 \mathrm{mmhr}^{-1}$ rainfall intensity (Figure 4) and $99.20 \mathrm{~mm} \mathrm{hr}^{-1}$ rainfall intensity (figure 5), soil loss rate for the three soils generally increased with slope steepness. Similarly, Huang (2001) had also found that soil loss rate for both soils increased gradually with slope steepness. Similar results were also reported by Fan and Wu (2001) as well as Meyer (1994).

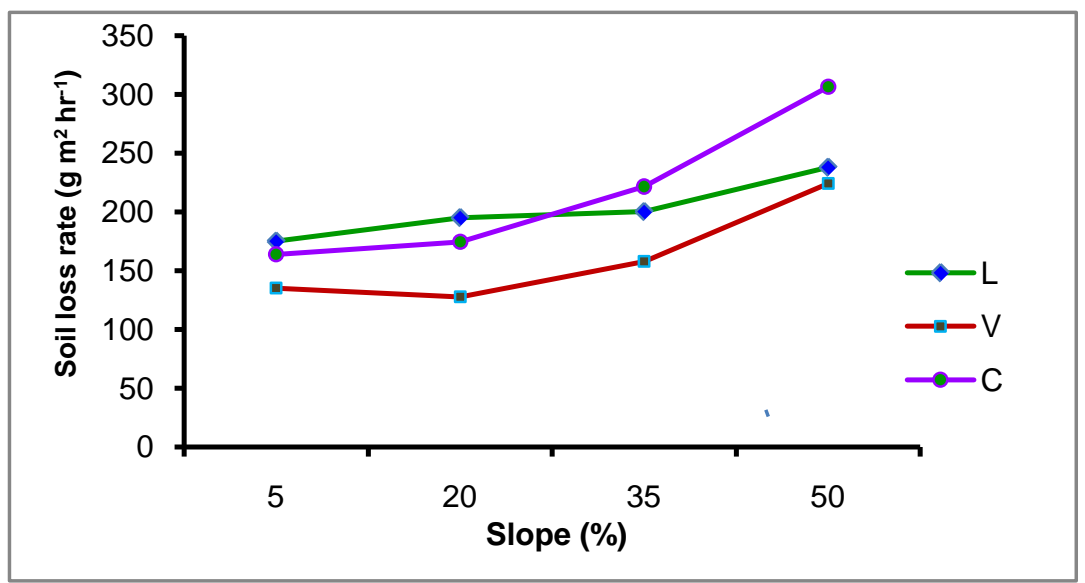

Figure 2: Interrill erosion Vs slope steepness at rainfall intensity of $25.67 \mathrm{~mm} \mathrm{hr}^{-1}$ (Where, L= Leptosols, $\mathrm{V}=\mathrm{Vertisols,} \mathrm{C}$ = Cambisols

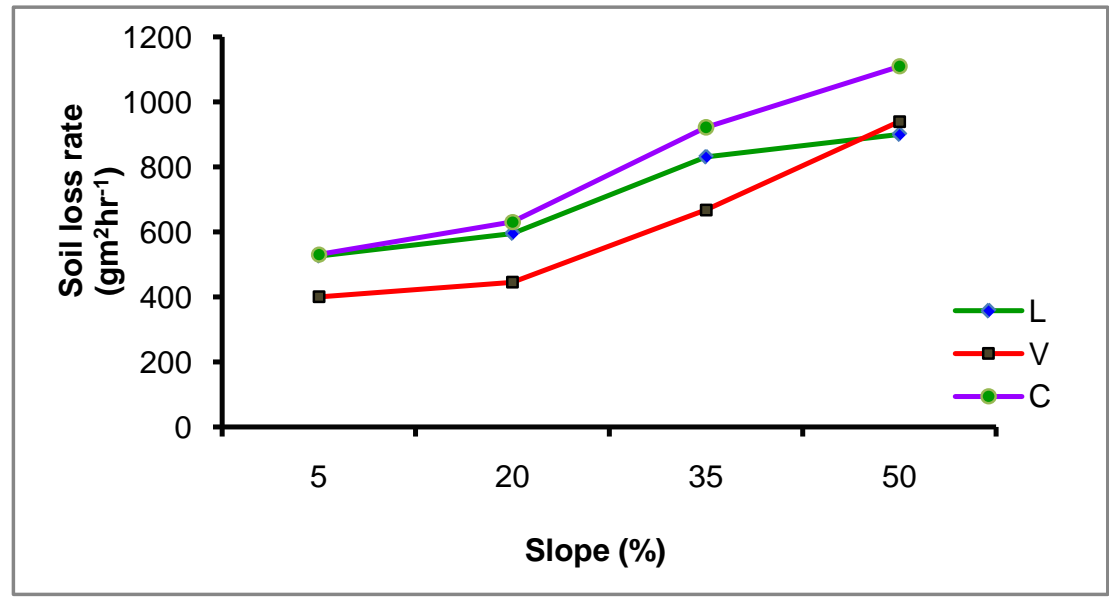

Figure 3: Interrill erosion Vs slope steepness at rainfall intensity of $52.14 \mathrm{~mm} \mathrm{hr}^{-1}$ (Where, L= Leptosols, V $=\mathrm{Vertisols,} \mathrm{C}$ = Cambisols)

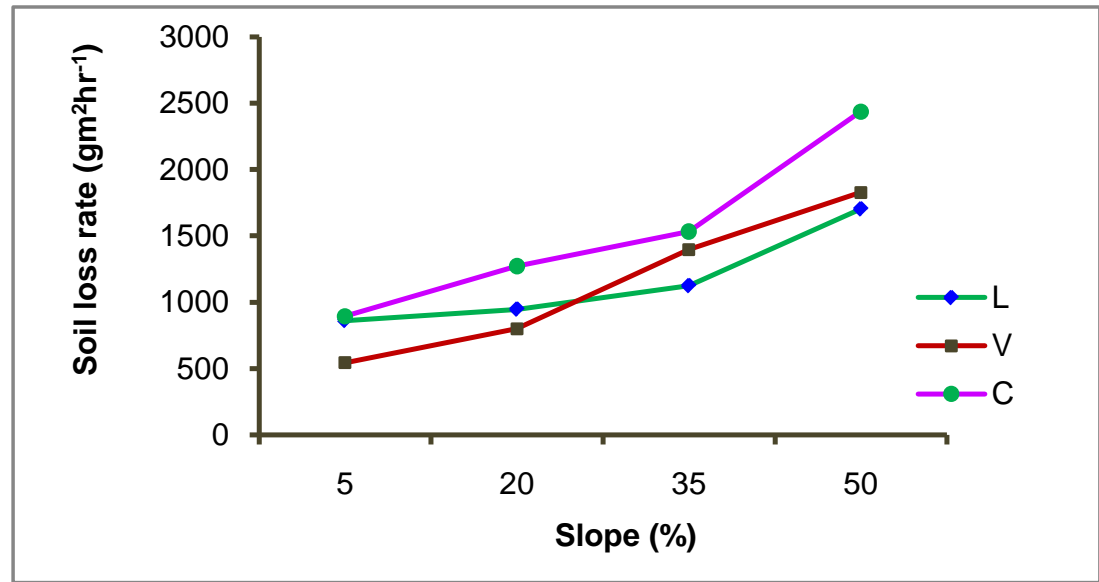

Figure 4: Interrill erosion Vs slope steepness at rainfall intensity of $73.50 \mathrm{~mm} \mathrm{hr}^{-1}$ (Where, L= Leptosols, V = Vertisols, C = Cambisols) 


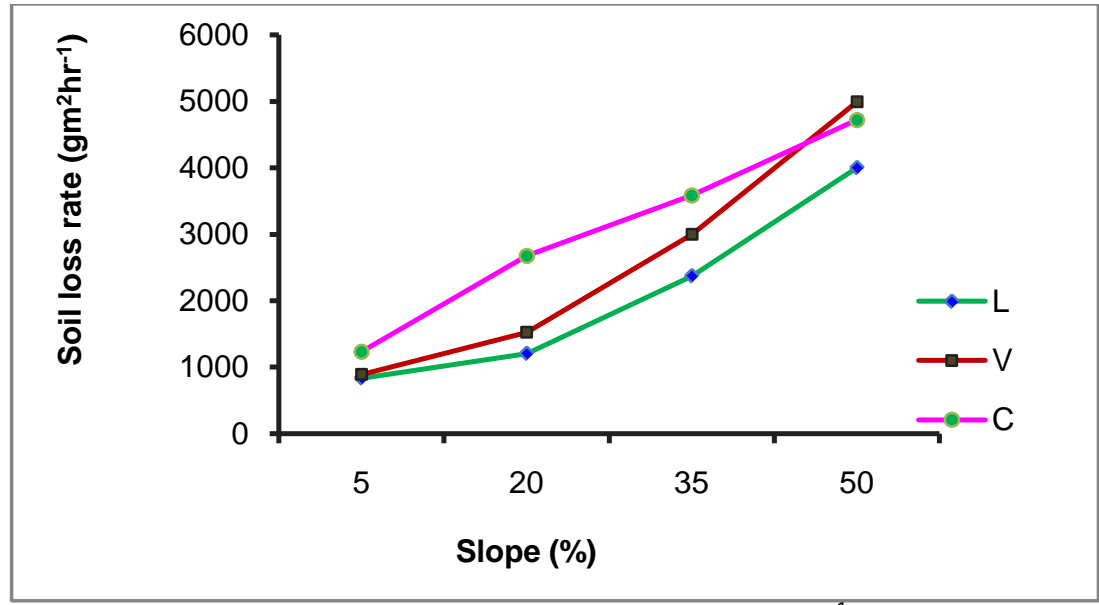

Figure 5: Interrill erosion Vs slope steepness at rainfall intensity of $99.20 \mathrm{~mm} \mathrm{hr}^{-1}$ (Where, L= Leptosols, $\mathrm{V}=\mathrm{Vertisols,} \mathrm{C}$ = Cambisols)

A closer observation of figures 2 to 5 revealed that soil loss mainly increased with an increase in slope steepness. At higher slope steepness, the erosion rate was mainly increased at a decreasing rate. This could be attributed to the reduction in the raindrop impact on soil surface due to higher surface inclination (Fan and $\mathrm{Wu}$, 2001). After investigating the effect of slope steepness on interrill erosion, it is worth considering some of the models relating interrill erosion and slope steepness that better describes the above relationships and incorporate it into other models to come out with an appropriate model encompassing all parameters under consideration. Some of the slope steepness factor equations selected for describing the effect of slope steepness on interrill erosion include:

$\mathrm{S}_{\mathrm{f} 1}=h+d \sin \theta+m \sin ^{2} \theta \quad($ Fox and Bryan,1999)
$\mathrm{S}_{\mathrm{f} 2}=\mathrm{h}+\sin ^{\mathrm{d}} \theta$ (Huang, 2001)

$\mathrm{Sf}_{3}=1.05-0.85 \exp (-4 \sin \theta)$ (Liebenow etal., 1990)

$\mathrm{S}_{\mathrm{f} 4}=\mathrm{S}^{\mathrm{d}}($ Van Liew and Saxton,2006)

$\mathrm{S}_{\mathrm{f5}}=3.0(\sin \theta)^{0.8}+0.56$ (Mc Cool et al., 1997)

Where, $\mathrm{S}_{\mathrm{f}}=$ Slope factor, $\mathrm{q} \theta=$ Slope angle $(\%), \mathrm{h}, \mathrm{d}$ and $\mathrm{m}$ are the best fit constants and exponents.

The above equations were tested for their ability to describe the effect of slope steepness on interrill erosion. A total of 15 models ( 5 slope factor equations * 3 models in which soil properties, rainfall intensity and runoff rates were included) were fitted to the experimental data and coefficients and exponents were estimated using a nonlinear regression analysis and the parameters estimated for the models were presented in Table 6.

Table 6: Estimated parameters for the models including soil properties and slope factor

\begin{tabular}{|c|c|c|c|c|c|c|c|c|c|c|}
\hline \multirow{2}{*}{ Models* } & \multicolumn{10}{|c|}{ Parameters } \\
\hline & $S_{f}$ & $\mathbf{a}$ & b & $\mathbf{n}$ & $\mathrm{x}$ & $y$ & $\mathbf{h}$ & d & $\mathbf{m}$ & $\mathrm{R}^{2}$ \\
\hline \multirow{5}{*}{$\begin{array}{c}\text { Model X } \\
\mathrm{E}_{\mathrm{i}}=\mathrm{al}^{\mathrm{b}} \tau^{\mathrm{y}}(\% \text { clay })^{\mathrm{x}} * \mathrm{~S}_{\mathrm{f}}\end{array}$} & $S_{f 1}$ & 2.150 & 1.836 & - & -0.675 & -0.088 & 4.598 & 0.520 & 0.036 & 0.87 \\
\hline & $S_{f 2}$ & 0.974 & 1. 308 & - & -0.627 & -1.492 & 9.745 & 0.580 & - & 0.91 \\
\hline & $S_{f 3}$ & 0.451 & 1.502 & - & -0.432 & -0.094 & - & - & - & 0.71 \\
\hline & $S_{f 4}$ & 0.912 & 1.385 & - & -0.033 & -0.632 & 1.424 & -0.180 & - & 0.86 \\
\hline & $S_{f 5}$ & 0.064 & 1.009 & - & -0.007 & -0.047 & - & - & - & 0.66 \\
\hline \multirow{5}{*}{$\begin{array}{c}\text { Model XI } \\
E_{i}=a l^{b} Q^{n} \tau^{y}(\% \text { clay })^{x} S_{f}\end{array}$} & $S_{f 1}$ & 2.606 & 0.594 & 0.217 & -0.318 & -0.933 & 4.639 & -1.803 & 0.585 & 0.94 \\
\hline & $S_{f 2}$ & 6.073 & 1.056 & 1.268 & -5.246 & -4.787 & 0.467 & -6.865 & - & 0.88 \\
\hline & $S_{f 3}$ & 1.702 & 0.021 & 0.079 & -0.251 & -0.044 & - & - & - & 0.72 \\
\hline & $\mathrm{S}_{\mathrm{f} 4}$ & 1.834 & 0.732 & 0.967 & -0.829 & -0.397 & -5.770 & 2.449 & - & 0.81 \\
\hline & $S_{f 5}$ & 0.907 & 0.006 & 0.281 & -0.407 & -0.039 & - & - & - & 0.67 \\
\hline \multirow{5}{*}{$\begin{array}{c}\text { Model XII } \\
\mathrm{E}_{\mathrm{i}}=\mathrm{al}^{\mathrm{b}} \mathrm{Q}^{\mathrm{n}} \mathrm{d}_{50^{\mathrm{y}}}(\% \text { clay })^{\mathrm{x}} \mathrm{S}_{\mathrm{f}}\end{array}$} & $S_{f 1}$ & 5.272 & 0.599 & 0.836 & -0.194 & -0.751 & 7.305 & 4.165 & 1.903 & 0.95 \\
\hline & $S_{f 2}$ & 1.901 & 0.562 & 0.966 & -0.475 & -1.096 & -17.35 & 0.590 & - & 0.88 \\
\hline & $S_{f 3}$ & 0.927 & 3.401 & 0.009 & 0.437 & -1.208 & - & - & - & 0.76 \\
\hline & $S_{f 4}$ & 11.480 & 1.469 & 0.995 & -0.656 & -6.402 & 20.880 & -0.561 & - & 0.81 \\
\hline & $S_{f 5}$ & 5.019 & 2.307 & 0.081 & -0.057 & -2.904 & - & - & - & 0.69 \\
\hline
\end{tabular}

$* \overline{E_{i}}\left(g^{-2} r^{-1}\right), I\left(\mathrm{~mm} \mathrm{hr}^{-1}\right), Q\left(\mathrm{~cm}^{3} \mathrm{~min}^{-1} \mathrm{~cm}^{-1}\right), d_{50}(\mu \mathrm{m}), \mathrm{T}\left(\mathrm{KNm}^{-2}\right)$, Slope steepness, $\mathrm{S}\left(\mathrm{mm}^{-1}\right), \theta=$ Slope angle $(\%)$, Sf represents Slope factors

Results of parameter estimation for the models (Table 6 ) showed that the $R^{2}$ value for each of the models varies. For a given model combined with different slope factor, variation in $R^{2}$ value was mainly due to variability in the potential of slope factor to predict interrill erosion under the concerned situation. The $\mathrm{R}^{2}$ values revealed that the potential effect of $S_{f 1}$, except $S_{\mathrm{f} 2}$ in the first model, on interrill erosion process was very high relative to the other slope factor equations in all the three models, while models incorporated into $S_{f 3}$ and $S_{f 5}$ had the lowest prediction potential. 


\section{Habtamu Adenew Weletu}

The Complete Empirical Equation for Interrill Soil Erosion

To develop the final empirical equation relating interrill erosion with rainfall intensity, soil properties, runoff rate and slope steepness, it could be feasible to select the model that best predicts interrill erosion. Accordingly, several models relating rainfall intensity, runoff rate and soil properties were tested and only three of them were selected depending on their prediction potential $\left(R^{2}\right.$ value). Parameters were estimated for empirical equations relating slope factors and other interrill erosion models selected to develop a powerful model for predicting interrill erosion as done by previous researchers (Fan and $\mathrm{Wu}, 2001$ ). Models incorporated with slope factor of the form $S_{\mathrm{f} 5}$ and $S_{\mathrm{f} 3}$ had low $\mathrm{R}^{2}$ values implying low prediction potential.

Models incorporated with slope factor equation of the form $S_{f 4}$ gave better $R^{2}$ value for model $X\left(R^{2}=0.86\right)$ than for models XI and XII for which the $R^{2}$ value was equal (0.81). Models incorporated with slope factor of the form $\mathrm{S}_{\mathrm{f} 2}$ gave equal prediction power for models XI and XII with $R^{2}=0.88$, while it has the highest $R^{2}$ value for model $X$ with $\left(R^{2}=0.91\right)$. For models $X I$ and $X I I$, interrill erosion models with slope factor of quadratic form $\left(S_{f 1}=h+d \sin \theta\right.$ $+m \sin ^{2} \theta$ ) have $R^{2}$ values which were sufficiently higher than that of the other models with $\mathrm{R}^{2}$ of 0.94 and 0.95 for models XI and XII respectively. Therefore, for the final model of interrill erosion, models which have the highest prediction potential (with highest $R^{2}$ values) were selected for further comparison and accordingly from the models
Sci. Technol. Arts Res. J., Jan-March 2016, 5(1): 51-60

presented in Table 6 , the following three models were selected. Finally the three models were of the form:

$E_{i}=a^{b} \tau^{y}(\% \text { clay })^{x} *\left(h+\sin ^{d} \theta\right) \quad\left(R^{2}=0.91\right)(X)$

$E_{i}=a^{b} Q^{n} \tau^{y}(\% \text { clay })^{x *}\left(h+d \sin \theta+m \sin ^{2} \theta\right)\left(R^{2}=0.94\right)(X I)$

$E_{i}=a l^{b} Q^{n} d_{50}{ }^{y}(\% \text { clay })^{x} *\left(h+d \sin \theta+m \sin ^{2} \theta\right)\left(R^{2}=0.95\right)$

(XII)

When the coefficients and exponents estimated for these models (Table 6) were substituted for each parameter, the final empirical equations become:

$E_{i}=0.974 I^{1.308} \tau^{-1.492}(\% \text { clay })^{-0.627} *\left(9.745+\sin ^{0.58} \theta\right)$

(XIII)

$\begin{aligned} \mathrm{E}_{\mathrm{i}}= & 2.606 \mathrm{I}^{0.594} \mathrm{Q}^{0.217} \tau^{-0.933}(\% \text { clay })^{-0.318 *}(4.639- \\ & \left.1.803 \sin \theta+0.585 \sin ^{2} \theta\right)\end{aligned}$

$E_{i}=5.272 l^{0.599} Q^{0.836} d_{50}{ }^{-0.751}(\% \text { clay })^{-0.194} *(7.305+$

$\left.4.165 \sin \theta+1.903 \sin ^{2} \theta\right)$

Even though the above models have high prediction potentials, it is still possible to select one model that will enable us to best predict interrill erosion at the study area. This could be done by comparing the models in terms of interrill erosion rates estimated from each of the models with the actual interrill erosion rates.

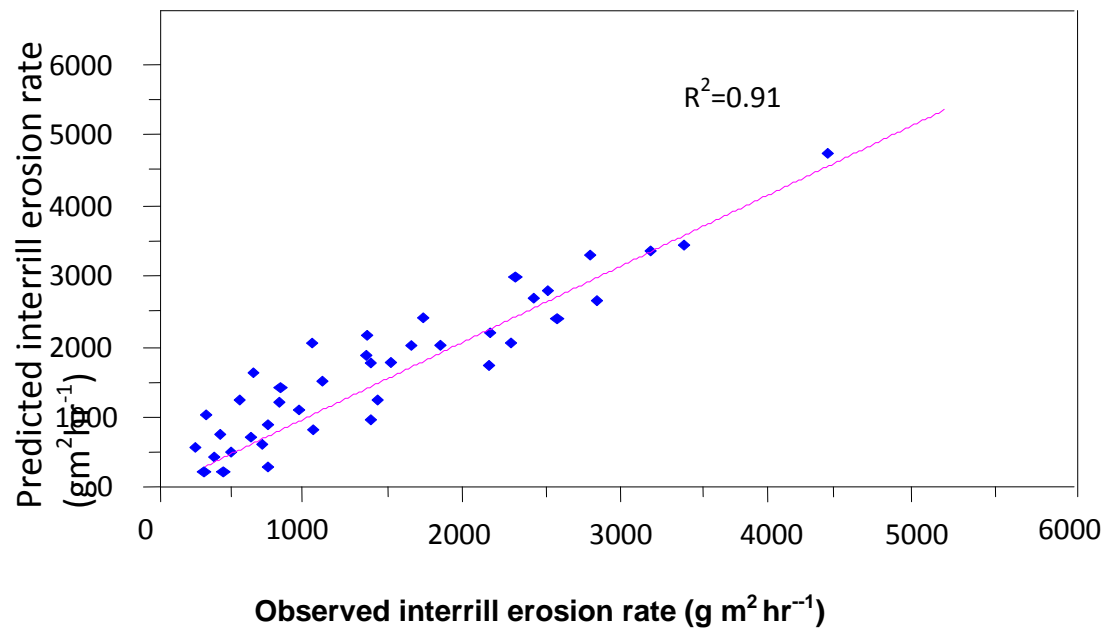

Figure 6: Predicted Vs observed interrill erosion rate for model $X$

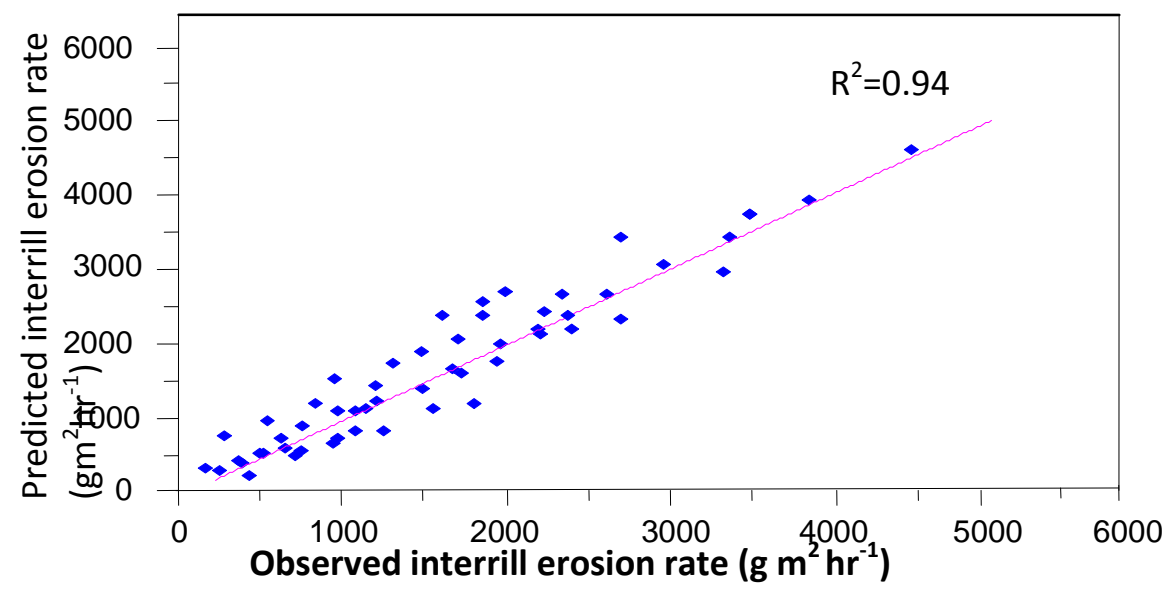


Figure 7: Predicted Vs observed interrill erosion rate for Model XI

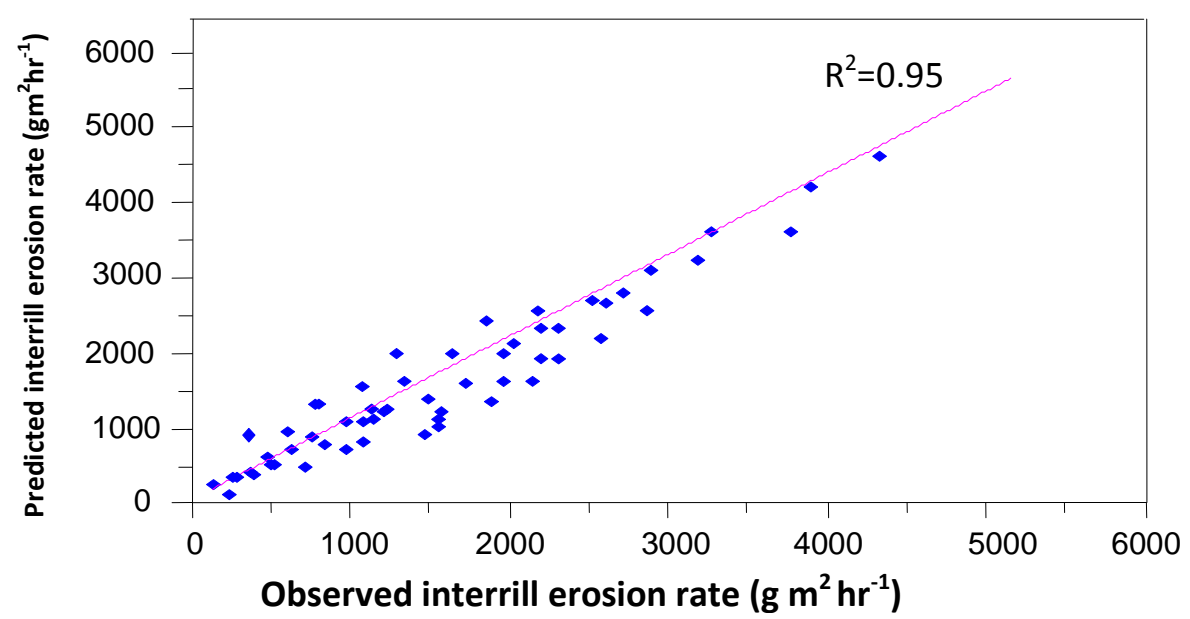

Figure 8: Predicted Vs observed interrill erosion rate for model XII

It could be seen that in case of model $X$, it nearly over estimated interrill erosion with $\mathrm{R}^{2}$ value of 0.91 (Figure 6). Most of the dots are above the 1:1 line indicating that for a given observed value, the model has over prediction of lower values. Besides, the line 1:1 is almost far to pass through the origin so that the observed and predicted values are not too much approaching each other. Similarly, in the case of model XI (Figure 7), most of the dots were above 1:1 line indicating that the model has a tendency of over predicting middle to higher values. But, the line $1: 1$ relatively tends to pass through the origin than in case of model $X$

In the case of model XII, most of the dots were below the 1:1 line (Figure 8), indicating that the model has under predicted lower values. Grosh and Jarrett (2004) reported that, models that nearly under predicted interrill erosion could be better recommended even though it has limitation than models that over estimate the soil loss. Therefore, from the three models, model XII $\left(R^{2}=0.95\right)$ has higher tendency to predict interrill erosion to the maximum of expected values as the 1:1line tends to pass through the origin than the rest two models implying that the predicted and observed values are nearly equal. So, it could be feasible using model XII to predict interrill erosion from crop lands of the study area, estimating environmental impacts and to account for land preparation methods in soil and water conservation efforts. Therefore, the empirical model selected for further recommendation could be of the form:

$$
\begin{aligned}
E_{i}= & 5.2721^{0.599} Q^{0.836} d_{50}{ }^{-0.751}(\% \text { clay })^{-0.194} *(7.305+ \\
& \left.4.165 \sin \theta+1.903 \sin ^{2} \theta\right)
\end{aligned}
$$

Where, $E_{i}=$ interrill erosion rate $\left(\mathrm{g} \mathrm{m}^{-2} \mathrm{hr}^{-1}\right), \mathrm{I}=$ rainfall intensity $\left(\mathrm{mm} \mathrm{hr}^{-1}\right), \mathrm{Q}=$ runoff rate $\left(\mathrm{cm}^{3} \mathrm{~min}^{-1} \mathrm{~cm}^{-1}\right), \%$ clay $=$ Percentage clay content, $d_{50}=$ median soil particle diameter $(\mu \mathrm{m}), \theta=$ slope angle (\%).

\section{CONCLUSIONS}

To obtain the complete empirical model that better describes interrill erosion in which the considered factors such as rainfall intensity, runoff rate, soil properties and slope were incorporated, different models were considered. The models are initially the one that better describes interrill erosion better even though they are from only limited factors that affects interrill erosion.
By using the data from runoff volume, runoff rate and some soil physical properties, coefficients and parameters were estimated for different combinations of the models. These models were compared in terms of their $R^{2}$ values and models with highest $\mathrm{R}^{2}$ values that better describes interrill erosion in the study area were selected. Later, models with highest performance were compared with each other in terms of interrill erosion rates estimated from each of the models with the actual interrill erosion rates and finally an empirical equation that better predicted interrill erosion was suggested as the final empirical relationship for quantifying interrill erosion. Unlike the previously developed models, this model incorporates several factors that affect interrill erosion which enable us to critically estimate soil loss rate by interrill erosion. This model can be applied for any environment with the estimation of the local constants.

\section{Conflict of Interest}

None declared.

\section{REFERENCES}

Agarwal, A., Dickinson, W.T. (2005). Effect of texture, rainfall and slope on rainfall interrill sediment transport. Nordic Hydrology 22: 227-242.

Bradford, J.M., Ferris, J.E., Remley, P.A. (1987). Interrill soil erosion processes: Effect of surface sealing on infiltration, runoff, and soil splash detachment to soil properties. Soil Science Society of America Journal 51(6): 1566-1571.

Fan, J.C., Wu, M.F. (2001). Estimation of interrill soil erosion on steep slopes. Transactions of the ASAE 44(6): 14711475.

Fox, D.M., Bryan, R.B. (1999). The relationship of soil loss by rainfall intensity between 1.5 and $30 \mathrm{~mm} \mathrm{~h}^{-1}$ interrill erosion to slope gradient. Catena 38:211-222.

Gete Z., Hurni, H. (2001). Implications of Land Use and Land Cover dynamics for mountain resource degradation in the northwestern Ethiopian highlands. Mountain Research and Development 21: 184-191.

Goff, B.F., Bent,G.C., Hart, G.E. (2000). Influence of rainfall intensity on interrill erodibility of two rangeland soils. Transactions of the ASAE 37(5): 1442-1447. 


\section{Habtamu Adenew Weletu}

Grosh, J.L., Jarrett, A.R. (2004). Interrill erosion and runoff on very steep slopes. Transactions of the ASAE 37(4): 1120-1130.

Huang, C. (2001). Empirical analysis of slope and runoff for sediment delivery from interrill areas. Transactions of the ASAE 59:982-990.

Jayawardena, A.W., Rezaur, R.B. (2006). Modeling interrill sediment delivery. Proceeding of the Seventh International Symposium on River Sedimentation. 16-18 Dec. Hong Kong.

Le Bissonnais, Y. (1996). Soil characteristics and aggregate stability. In: M. Aggassi (ed.). Soil Erosion, Conservation, and Rehabilitation, 41-60. Marcel Dekker. New York.

Le Bissonnais, Y., Singer, M.J. (2003). Seal formation, runoff and interrill erosion for Seventeen California soils. Transactions of the ASAE 57(1): $224-230$.

Liebenow, A.M., Elliot, W.J., Laflen, J.M., Kohl, K.D. (1990) Interrill erodibility: Collection and analysis of data from cropland soils. Transactions of the ASAE 33(4): 18701899.
Sci. Technol. Arts Res. J., Jan-March 2016, 5(1): 51-60

McCool, D.K., Brown, L.C., Foster, G.R. (1997). Revised slope steepness factor for the universal Soil Loss Equation. Transactions of the ASAE 30: 1387-1394.

Mengistu B. (2003). Study on the Effect of Slope Steepness and Antecedent Soil Moisture Content on Interrill Erosion. MSc Thesis, Haramaya University, 112p

Meyer, L.D. (1994). Rainfall simulator for soil erosion research. In: R. Lal, (ed.). Soil Erosion Research Methods, 83-91.

SCRP, 1990. Soil loss and runoff assessment findings. Soil conservation research project (SCRP). Addis Abeba, Ethiopia.

Sheridan, G.J., So, H.B., Loch, R.J., Walker, C.M. (2007). Estimation of erosion model erodibility parameters from media properties. Aust. J. Soil Res. 39: 140-187.

Van Liew, M.W., Saxton, K.E. (2006). Slope steepness and incorporated residues effects on interrill erosion. Transactions of the ASAE 26(6):1738-1743.

Zhang, X.C., Nearing, M.A., Miller, W.P., Norton, L.D., West, L.T. (2003). Modeling Interrill sediment delivery. Soil Science Society of America Journal 62(2): 502-507. 